\title{
An Assessment of Culturally Appropriate Design: A Malaysian University Context
}

\author{
https://doi.org/10.3991/ijim.v12i2.8014 \\ Shamsul Arrieya Ariffin( ${ }^{\bowtie}$, Azniah Ismail, \\ Maizatul Hayati Yatim, Salman Firdaus Sidek \\ Universiti Pendidikan Sultan Idris, Tanjong Malim, Perak, Malaysia \\ shamsul@fskik.upsi.edu.my
}

\begin{abstract}
The growing popularity of mobile devices, together with the constant technological improvement of mobile websites and applications informed about the quality of the user interface design. However, the particularities of mobile devices require special attention in terms of their usability aspects, such as culture. Therefore, this study evaluated the use of culturally appropriate design guidelines for a mobile learning web site. The research methodology used comprised a survey from heuristic evaluation questionnaires with undergraduate students. This research captured the students' experiences in using the MLearn website of Universiti Pendidikan Sultan Idris, Malaysia. From the study, the lowest ranking is realistic error management at 3.5, and the highest is suitable content for local culture at 4.6. This study affirmed that general usability and cultural principles in design are important for a usable mobile learning website system in a local university context.
\end{abstract}

Keywords-Usability, Mobile Learning, Culturally Appropriate Design

\section{Introduction}

Mobile learning is a fairly new approach in the educational paradigm where learning is concerned, particularly in terms of the website user interface design. The mobile learning process may involve the usage of mobile devices, such as mobile phones, or laptops, etc. In addition, mobile learning is also known as the process involving conversations across multiple contexts among people and personal interactive technologies [18].

As users interact with mobile learning websites on a variety of smartphones or other Internet-capable mobile devices, all with different hardware and software, it is commonly considered best practice to perform usability tests prior to the launch of a new website to assess its user-friendliness. Checking the usability of a system can be done from the evaluation of various application techniques [15]. One such technique that can be used is the heuristic evaluation of usability, and interview sessions with the participants. An interaction tool must be a very efficient system provide satisfactory interaction through its usability [4]. 


\section{$2 \quad$ Literature Review}

\subsection{Mobile Learning}

Mobile learning is defined as "Learning across multiple contexts, through social and content interactions, using personal electronics devices" [3]. Additionally, mobile learning takes place when the learner is not fixed in a predetermined location, or when the learner "takes advantage of the learning opportunities offered by mobile technology" [14]. For example, mobile learning should be restricted to learning on small and portable devices [7], while, the nature of mobile addresses "mediated learning through mobile technology" [22].

The role of mobile learning can improve access to education in developing countries in Asia. Mobile learning makes education more accessible in that it enables learners to pursue their learning according to their own schedule. The portability of mobile technology means that mobile learning is not bound by fixed class times. This complements the research of six mobile learning projects that took place in five developing countries in Asia - the Philippines, Mongolia, Thailand, India, and Bangladesh [21]. Similar to most developing countries, mobile learning interventions are being undertaken in Asia, and such development indicates that the region could become a global leader in the educational uses of mobile devices [11]. Moreover, mobile learning can facilitate design for authentic learning, meaning learning that targets real-world problems and involves projects that are of relevance and interest to the learner [8].

Distance learning is not a recent phenomenon to Malaysians [6]. Many individuals, especially those who are still working and aspire to be successful in their career development, enrolled for external degrees offered by reputable universities in the 1960s or earlier. Mobile learning initiatives in Malaysia are being undertaken mainly by universities, colleges, and business enterprises [6]. Mobile learning is rising in Malaysian society, particularly among those involved in education, which may involve many mobile applications including local websites [13]. In addition, mobile learning can be extended to improve the quality of the mobile applications via usability with culturally appropriate design guidelines (CADG).

\subsection{Mobile Usability and cultural design guidelines}

Mobile usability can be considered to be a specialty in the usability field that is currently emerging [12]. One study in the Human Computer Interaction (HCI) field found that to produce computer systems with the appropriate usability, it is important to understand the psychological, ergonomic, organizational, and social factors that define how people work. For instance, mobile usability reflects the perceived ease of navigating the site or making purchases through the Internet, which is considered to be a critical factor in the development of electronic commerce [5]. Likewise, mobile application activities enable students to study local cultural subjects in a variety of ways. For example, four (4) main culturally appropriate design principles can be ap- 
plied when developing the local content of mobile devices for mobile learning purposes [1].

\subsection{Four existing guidelines for mobile application}

There are four (4) existing guidelines for comparison of Culturally Appropriate Design Guidelines, for mobile applications - Shneiderman's Golden Rules of interface design (SGR), Human-Centered Design (HCD) (ISO standard 13470), Mobile Web Best Practices 1.0 (W3CBP), and Nielsen. A comparison between the four existing guidelines for mobile application development with CADG is illustrated in Table 1 .

Table 1. Comparison between four existing guidelines for mobile application development with CADG

\begin{tabular}{|l|c|c|c|c|}
\hline \multicolumn{1}{|c|}{ CADG } & SGR & Nielsen & HCD & W3CBP \\
\hline Accessibility & & $\checkmark$ & & \\
\hline Consistency & $\checkmark$ & $\checkmark$ & & $\checkmark$ \\
\hline Good Ergonomic and Minimalist User Interface Design & $\checkmark$ & $\checkmark$ & $\checkmark$ & $\checkmark$ \\
\hline Readability and Ease of Recall & & $\checkmark$ & & \\
\hline Efficiency and Flexibility & & $\checkmark$ & & \\
\hline Realistic Error Management & $\checkmark$ & $\checkmark$ & & $\checkmark$ \\
\hline Suitable Content for Local Cultural & & & & \\
\hline Aesthetic Value According to Local Culture & & $\begin{array}{c} \\
\text { (Not for LC) }\end{array}$ & & \\
\hline Local Language & & & & \\
\hline Philosophical Values & & & & \\
\hline
\end{tabular}

\section{Research Methodology}

The research methodology focuses on the strategy for assessing the mobile learning website system of MobiLearn. MobiLearn is a local university mobile application website developed for a local university. In this study, participants were given one week to learn and familiarize themselves with this application. This research conducted a heuristic evaluation by giving two (2) classes of 60 participants' questionnaires. During the first session, the two classes of participants focused on the briefing session about the MobiLearn application function before they could answer the questionnaire. This session only took 30 minutes for each class. After one week, the participants were given the questionnaire. In figure 1, the Methodology diagram, Thematic Analysis is the methodology used by the researcher to examine the discussion data for the Culturally Appropriate Design Guideline principles. Themes were generated as they emerged from the research data. This paper discusses the descriptive results from the heuristic evaluation. The surveys are divided into sections of the design principles: Accessibility, Consistency, Good Ergonomics, Readability, Efficiency \& Flexibility, Error Prevention, Suitable Content, Aesthetic Value, Language, and Local Philosophy 


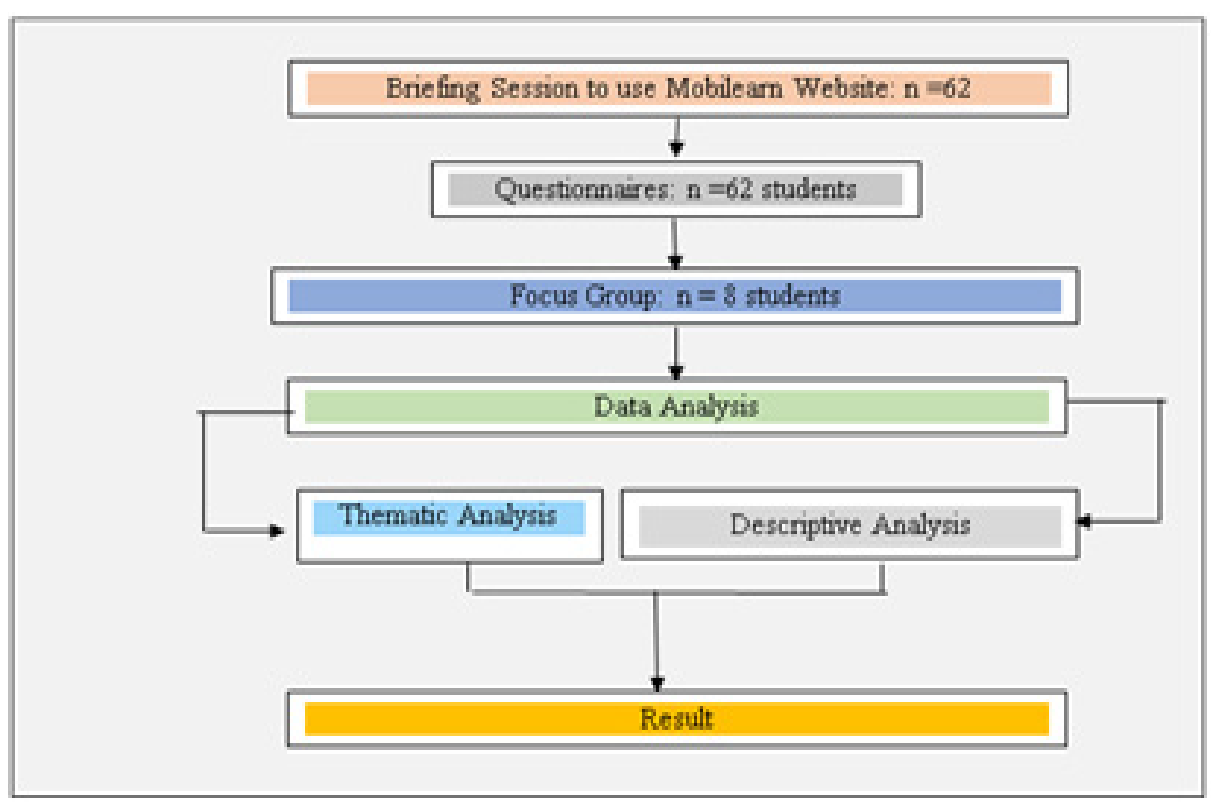

Fig. 1. Methodology Diagram

Table 2. Mobile application development with CADG [1]

\begin{tabular}{|l|l|}
\hline \multicolumn{1}{|c|}{ Principle } & \multicolumn{1}{c|}{ Description } \\
\hline Accessibility & $\begin{array}{l}\text { Refers to the inclusive practice of removing barriers that prevent interaction } \\
\text { with, or access to websites, by people with disabilities. When sites are correctly } \\
\text { designed, developed and edited, all users have equal access to information and } \\
\text { functionality. }\end{array}$ \\
\hline Consistency & A harmonious uniformity or agreement among things or parts. \\
\hline Good ergonomics & $\begin{array}{l}\text { Design factors, as for the workplace, intended to maximize productivity by } \\
\text { minimizing operator fatigue and discomfort. }\end{array}$ \\
\hline Readability & Refers to the way in which words and blocks of type are arranged on a page. \\
\hline Efficiency \& Flexibility & $\begin{array}{l}\text { Efficiency is a measure of how well a website does what it should do. } \\
\text { Flexibility may refer to hardware, software, or a combination of the two. It } \\
\text { describes a device or program that can be used for multiple purposes, rather } \\
\text { than a single function. }\end{array}$ \\
\hline Error prevention & $\begin{array}{l}\text { Error prevention practices as part of the application design mean implementing } \\
\text { specific design techniques and using the capabilities of the product to help } \\
\text { prevent system and application errors. }\end{array}$ \\
\hline Suitable content & Suitable content means the content suits the culture or the environment. \\
\hline Aesthetic Value & Focuses on the study of the beauty or aesthetics of the user interface. \\
\hline Language & The system of communication used by a particular community or country. \\
\hline Local philosophy & The study of ideas about knowledge, truth, and the nature and meaning of life. \\
\hline
\end{tabular}




\section{$4 \quad$ Findings/Results}

This research focuses on the descriptive quantitative evaluation from the students for the Mobilearn mobile learning website system UPSI. This research has undergone several phases of evaluation for the cultural aspect and general usability principles.

\subsection{Results from Ranking Evaluation}

The data collected from the heuristic evaluation questionnaires with all the participants were analyzed and discussed. Being supported by the quantitative computations and statistical conclusions, it can be concluded that the culturally appropriate design can be improved. There are usability challenges for students in using this new mobile learning system. Both the general usability and cultural aspects are also proven to complement each other and have a significant effect on this mobile application.

Table 3. The Ranking and Mean for the Guideline Principles in Ascending Order

\begin{tabular}{|c|l|c|}
\hline $\begin{array}{c}\text { Ranking } \\
\text { (Lowest to Highest) }\end{array}$ & \multicolumn{1}{|c|}{ Guideline Principles } & Total Mean \\
\hline 1 & Realistic error management & 3.4758 \\
\hline 2 & Efficiency and flexibility & 3.8852 \\
\hline 3 & Aesthetic value according to local culture & 3.9234 \\
\hline 4 & Readability and ease of recall & 3.9516 \\
\hline 5 & Consistency & 4.0538 \\
\hline 6 & $\begin{array}{l}\text { Good ergonomic and minimalist user interface } \\
\text { design }\end{array}$ & 4.1237 \\
\hline 7 & The local philosophy has local culture value & 4.1371 \\
\hline 8 & Accessibility & 4.2903 \\
\hline 9 & The language use is for local culture & 4.3387 \\
\hline 10 & Suitable content for local culture & 4.6290 \\
\hline
\end{tabular}

Table 3 shows the ranking of the application based on the mean from the lowest ranking to the highest. The ranking of each item for each principle was averaged to provide an overall evaluation of whether or not students agreed with all the statements. It can be seen that the lowest ranking is realistic error management with a mean of 3.4758 and the highest is suitable content for local culture with 4.6290.

Based on the results in Table 3 it can be concluded that this website mobile learning system is very suitable for the local culture, as, from the evaluation, the cultural design principle receives the highest ranking for suitable content for local culture. However, the mobile application also lacks the realistic error management principle in the design having received the lowest ranking through the evaluation. 


\section{Discussion}

The research literature review could lead to opportunities and challenges that would influence the cultural perspectives in the Mobilearn mobile learning website system UPSI. From the data collected through this research, this website mobile application is very suitable for the local culture. The cultural principle for local content received the highest ranking at 4.62 but lacked realistic error management, which received the lowest ranking score of only 3.47. Although the researcher faced avoidable challenges and constraints throughout this research, these challenges and constraints did not become a barrier to the researcher in reaching the objectives of this research. Challenges, such as limited cultural and philosophy policies in the application, were raised by the participants, as well as technical issues, such as wireless coverage, lack of training, and many more. Another main issue was the lack of local content for mobile applications.

The lack of local content is the main motivation and concern of this study. From the research, it can be concluded that there is a lack of local content [9], and lack of quality educational content for Asia for Mobile learning websites [20].

Table 4. Culturally Appropriate Design Guidelines

\begin{tabular}{|c|l|l|}
\hline No & Description & \multicolumn{1}{|c|}{ Culturally Appropriate Design Guidelines } \\
\hline 1 & General Usability & Accessibility \\
\hline 2 & General Usability & Consistency \\
\hline 3 & General Usability & Good Ergonomic and Minimalist User Interface Design \\
\hline 4 & General Usability & Readability and Ease of Recall \\
\hline 5 & General Usability & Efficiency and Flexibility \\
\hline 6 & General Usability & Realistic Error Management \\
\hline 7 & Cultural Aspect & Suitable Content for Local Cultural \\
\hline 8 & Cultural Aspect & Aesthetic Value According to Local Culture \\
\hline 9 & Cultural Aspect & Local Language \\
\hline 10 & Cultural Aspect & Philosophical Values \\
\hline
\end{tabular}

\section{Conclusion}

From this study, the capturing of user experience was quite difficult, because of the many different factors in the user-product interaction. For the evaluation, these factors should be clarified, and a goal for the test defined in a test plan is recommended for future studies. This may help make the evaluation more systematic.

This research focused on the descriptive evaluation from the students for the Mobilearn UPSI Application. This research affirmed the significance of the cultural aspect and general usability principles for a local mobile website application. 


\section{$7 \quad$ References}

[1] Ariffin, S. A., \& Dyson, L. E. (August, 2015) Culturally Appropriate Design of Mobile Learning Applications in the Malaysian Context. In International Conference on CrossCultural Design (pp. 3-14). Springer, Cham. https://doi.org/10.1007/978-3-319-20934-0 1

[2] Brady, F., \& Dyson, L. E.(2010) A comparative study of mobile technology adoption in remote, Australia.

[3] Crompton, H. A Historical overview of m-learning: Toward learner-centered education. In Berge, Z.L. and Muilenburg, L.Y. (Eds.), Handbook of Mobile Learning (pp. 3-14). New York, NY: Routledge, 2007

[4] Cybis, W., Betiol, A. H., \& Faust, R. Ergonomics and usability: knowledge, methods and applications, 2007.

[5] Flavián, C., Guinalíu, M., \& Gurrea, R. The role played by perceived usability, satisfaction and consumer trust on website loyalty. Information \& Management, 43(1), 1-14, 2006. https://doi.org/10.1016/j.im.2005.01.002

[6] Hazirah, N., \& Seman, B. A. Perceptions of cognitive science majors toward online learning at Universiti Malaysia Sarawak, 2011.

[7] Keegan, D. (Ed.). Theoretical principles of distance education. Routledge, 2005.

[8] Kukulska-Hulme, A. Mobile usability in educational contexts: what have we learnt. The International Review of Research in Open and Distributed Learning, 8(2), 2007. https://doi.org/10.19173/irrodl.v8i2.356

[9] Lim, K. Y. 'Minister Speech. The Tele management Forum's Asean Regional Summit,' [Online], [Retrieved August 15, 2010], http://www.tmforum.org/WhyAttend/2719/ home.html, 2005.

[10] Liu, Y., Zoe, K., Sung, R., Lim, T., Louchart, S., Ritchie, J., \& Poirson, E. (2015). Human Centred Design.

[11] Motlik, S. Mobile learning in developing nations. The International Review of Research in Open and Distributed Learning, 9(2), 2008. https://doi.org/10.19173/irrodl.v9i2.564

[12] Nielsen, J Mobile usability update. URL: http://www. nngroup.com/articles/mobileusability-update/[accessed 2014-02-21], 2011.

[13] Nordin, N. M., Embi, M. A., Norman, H., \& Panah, E. A Historical Review of Mobile Learning Research in Malaysia and Its Implications for Malaysia and the Asia-Pacific Region. In Mobile Learning in Higher Education in the Asia-Pacific Region (pp. 137-150). Springer, Singapore, 2017. https://doi.org/10.1007/978-981-10-4944-6 7

[14] O'Malley, C., Vavoula, G., Glew, J. P., Taylor, J., Sharples, M., Lefrere, P.,\& Waycott, J. Guidelines for learning/teaching/tutoring in a mobile environment, 2005.

[15] Preece, J., Y. Rogers, and H. Sharp, Interaction design: beyond human-computer

[16] Interaction, 2002: John Wiley \& Sons, Inc.

[17] Rabin, J., \& McCathieNevile, C. (2008). Mobile web best practices 1.0. Basic guidelines, de http://www. w3. org/TR/2008/REC-mobile-bp-20080729.

[18] Seong, D. S. K. (2006, October). Usability guidelines for designing mobile learning portals. In Proceedings of the 3rd international conference on Mobile technology, applications \& systems (p. 25). ACM.

[19] Sharples, M., Taylor, J., \& Vavoula, G. Towards a theory of mobile learning. In Proceedings of mLearn, Vol. 1, No. 1, pp. 1-9, October. 2005.

[20] Shneiderman, B. (2010). Designing the user interface: strategies for effective humancomputer interaction. Pearson Education India.

[21] So, H. J. Turning on mobile learning in Asia: Illustrative initiatives and policy implications. Policy focus: UNESCO working paper series on mobile learning, 1, 1-32, 2012. 
[22] Valk, J. H., Rashid, A. T., \& Elder, L. Using mobile phones to improve educational outcomes: An analysis of evidence from Asia. The International Review of Research in Open and Distributed Learning, 11(1), 117-140, 2010. https://doi.org/10.19173/irrodl.v11i1.794

[23] Winters, N. What is mobile learning? In M. Sharples (Ed.), Big issues in mobile learning: Report of a workshop by the kaleidoscope network of excellence mobile learning initiative. University of Nottingham, 2006.

[24] Young, P. A. (2008). Integrating culture in the design of ICTs. British Journal of Educational Technology, 39(1), 6-17.

\section{Authors}

Shamsul Arrieya Ariffin, Azniah Ismail, Maizatul Hayati Yatim and Salman Firdaus Sidek are with the Faculty of Art, Computing and Creative Industry, Universiti Pendidikan Sultan Idris, Tanjong Malim, Perak, Malaysia.

Article submitted 23 November 2017. Final acceptance 23 February 2018. Final version published as submitted by the authors. 